\title{
Assessing biofouling on polyamide reverse osmosis (RO) membrane surfaces in a laboratory system
}

\author{
Mohiuddin Md. Taimur Khan ${ }^{\mathrm{a}, *}$, Philip S. Stewart ${ }^{\mathrm{b}}$, David J. Moll ${ }^{\mathrm{c}}$, William E. Mickols ${ }^{\mathrm{d}}$, \\ Mark D. Burr ${ }^{b}$, Sara E. Nelson ${ }^{b}$, Anne K. Camper $^{\mathrm{b}}$ \\ a Department of Civil Engineering, MSC01 1070, University of New Mexico, Albuquerque, NM 87131-0001, USA \\ b Center for Biofilm Engineering, Montana State University, Bozeman, MT 59717-3980, USA \\ c The Dow Chemical Company, Larkin Laboratory, 1691 North Swede Road, Midland, MI 48674, USA \\ ${ }^{\mathrm{d}}$ The Dow Chemical Company, FilmTec R E D, 5230 73rd St., Edina, MN 55439, USA
}

\section{A R T I C L E I N F O}

\section{Article history:}

Received 24 July 2009

Received in revised form 24 November 2009

Accepted 3 December 2009

Available online 11 December 2009

\section{Keywords:}

Biofouling

Cryo-section

Live and dead cells

Reverse osmosis membrane

Hydrophobicity

X-ray photoelectron spectroscopy

\begin{abstract}
A B S T R A C T
Biofouling of reverse osmosis (RO) membranes is a major impediment in both wastewater reuse and desalination of sea/brackish waters. A benefit to the industry would be a simple screening approach to evaluate biofouling resistant RO membranes for their propensity to biofoulants. To observe the relationship between initial membrane productivity and control of biofilm formation governed by surface modification to the aromatic polyamide thin-film composite RO membranes, three different RO membranes developed by the FilmTec Corporation including FilmTec's commercial membrane BW30 (RO\#1) and two experimental membranes ( $\mathrm{RO} \# 2$ and \#3) were used. RO \#2 and RO \#3 were modified with a proprietary aliphatic group and with an extra proprietary aromatic group, respectively. Membrane swatches were fixed on coupons in rotating disk reactor systems without filtration and exposed to water with indigenous organisms supplemented with $1.5 \mathrm{mg} / \mathrm{L}$ organic carbon under continuous flow. After biofouling had developed, the membranes were sacrificed and subjected to several analyses. Staining and epifluorescence microscopy revealed more cells on RO \#2 and \#3 compared to RO \#1. Based on image analysis of $5-\mu \mathrm{m}$ thick stained biofoulant cryo-sections, the accumulation of hydrated biofoulants on RO \#1 and \#3 were from 0.87 to $1.26 \mu \mathrm{m} /$ day, which was lower than that on RO\#2 (2.19 $\mu \mathrm{m} /$ day). Biofoulants increased the hydrophobicity of RO \#2 to the greatest amount, up to $32^{\circ}$, as determined by contact angle. In addition, a wide range of changes of the chemical elements of the RO surfaces was observed with X-ray photoelectron spectroscopy analysis. RO \#2 with the highest initial membrane productivity showed the poorest biofouling resistance. A combination of these novel approaches showed good agreement and suggested that membrane productivity, heterogeneity of anti-biofouling agents on membrane surface, stability of surface chemical elements and the role of virgin RO surface hydrophobicity should be jointly considered during the development of anti-biofouling polyamide thin-film RO surfaces.
\end{abstract}

Published by Elsevier B.V.

\section{Introduction}

The decrease in performance of reverse osmosis (RO) membranes in wastewater reuse and purification of sea/brackish water systems due to biofouling is a major concern [1-3]. The biofouling phenomenon can have the following adverse effects on RO systems: membrane flux decline, increased differential pressure and feed pressure, membrane biodegradation, increased salt passage, substantial decrease in boron rejection, and increased energy

\footnotetext{
* Corresponding author. Tel.: +1 505277 1048; fax: +1 5052771988 . E-mail addresses: mmtkhan@unm.edu, taimur2000@hotmail.com (M.Md.T. Khan), phil_s@erc.montana.edu (P.S. Stewart),djmoll@dow.com (D.J. Moll), wemickols@dow.com (W.E. Mickols), mark_b@erc.montana.edu (M.D. Burr), snelson@erc.montana.edu (S.E. Nelson), anne_c@erc.montana.edu (A.K. Camper).
}

requirements [4-7]. The long-term effect of flux decline in RO is primarily due to combined deposition of feedwater components rejected by the membrane (sparingly soluble inorganic compounds, colloidal or particulate matter, and dissolved organics) and/or to the attachment and growth of microorganisms (biofilm formation) on the RO surface $[8,9]$. The decline in membrane performance can be attributed to the increase in both the hydraulic resistance and the trans-membrane osmotic pressure of the fouled membrane [6]. These phenomena may be due to the narrowing of the flow channels across the RO membrane surface caused by biofouling [10,11].

Biofouling is the one least understood and controlled fouling mechanisms and the multiplication of cells and simultaneous production of EPS inside the biofoulants on the membrane decrease the membrane productivity $[12,13]$. RO systems used for water and wastewater treatment are exposed to microorganisms and their byproducts which cause this biofouling [14]. Bacterial cell surfaces 
contain lipopolysaccharides (LPS) and extracellular polymeric substances (EPS), which play a role in bacterial-surface interactions [15] and are probable players in membrane fouling. Interestingly, most of the biofouling studies $[12,13,16,17]$ focused on the EPS or LPS substances and did not focus on the distribution of the bacteria in the fouling layer. The bacteria and EPS can cause changes in surface composition of membranes, which was demonstrated by Schneider et al. [18], affecting membrane permeability and filtration quality. Therefore, during the development of biofouling resistant RO membrane surfaces the investigation of biofouling potentials, the distribution of bacteria, their polymers inside the biofilm and the resultant surface chemical composition changes on those RO surfaces are important parameters to consider.

The state-of-art techniques for biofouling control are disinfection using hypochlorite, ozone, bromine, chlorine dioxide and ultraviolet light [19]. The application of biocides, however, has to be considered carefully and failures have been reported when massive biofouling occurred despite chlorination [20]. RO surface modification is another potential option for preparing antifouling surfaces by improving the hydrophilicity and/or charge properties $[21,22]$. Surface modification methods range from simple physical adsorption [21,23] to chemical bond formation [24-27]. In addition, covalent grafting methods can be done by chemical coupling [25], UV-induced [26], or may be plasma-initiated [27]. Among various hydrophilic monomers used for surface grafting, poly(ethylene glycol) (PEG) and its derivates were widely used [28,29]. These approaches of surface modification increase the antifouling properties of membranes.

In a broad sense, case studies of RO and nanofiltration (NF) membrane biofouling have been used to establish protocols for diagnosis, prediction and prevention of biofouling [5,6,30]. On a more fundamental level, several studies on biofouling have used different bacterial strains [31-33], direct observation of bacteria on the top layer of biofilm [34], and various analytical techniques [35-40] for elucidating specific physical and chemical surface properties of membranes using different types of RO membranes in filtration mode. While the above studies provided useful qualitative information on RO membrane flux decline, none quantified the biofoulants correlating their structures and distributions on the RO surfaces with simultaneous changes of surface chemical properties and hydrophobicity for screening novel RO surfaces (new polymers, incorporated biocides, or other novel chemistries). Furthermore, the relationship between biofouling resistant RO surfaces and their initial productivity has not been explored.

As a first step in assessing relative biofouling susceptibility and the ability to maintain initial surface chemical composition of novel membranes with various membrane productivities, it would be helpful to have accurate and more information of the fundamentals of RO biofoulants and their effects on membrane surface properties prior to more detailed and expensive testing. This concept should be coupled with information on RO membrane productivity, cost effectiveness and target materials rejection modeling to develop more efficient polymer chemistries for the development of next generation and low-cost RO surfaces. To address these needs, the objectives of this study were to: (1) visualize and obtain quantitative comparisons of biofouling formation, structure and control by three different biofouling resistant polyamide RO surfaces and (2) estimate and correlate the biofilm parameters with the change of hydrophobicity and surface chemical compositions.

\section{Materials and methods}

\subsection{Membrane types, reactor setup and sample preparations}

Three different types of aromatic polyamide thin-film composite RO membranes provided by FilmTec Corporation (Dow Chemical
Company, USA) were used, including FilmTec's commercial membrane BW30 (RO\#1) and two experimental RO membranes (RO \#2 and \#3). All of these RO surfaces had a polysulfone layer under the aromatic polyamide thin-film layer.

A polyester layer supported the polysulfone layer. All membranes were surface modified on the top of the polyamide layer. These modified surfaces were highly water permeable and the surface modification was responsible for anti-biofouling properties of the RO surfaces. These RO surfaces had varied ranges of surface modifications while the support layers (polysulfone support and PET non-woven) were the same and further changes of support structures were within manufacturing variations. RO \#2 had extra aliphatic groups and RO \#3 had extra aromatic groups on the top layer of polyamide surfaces. Detailed information about the heterogeneity and chemistry of these surfaces is proprietary.

General performances of these surfaces were evaluated at 125 psi applied pressure and $2000 \mathrm{ppm}$ initial concentration of $\mathrm{NaCl}$ dissolved in DI water, the membrane productivity and membrane water permeability coefficient/\% salt passage (A-value/\%SP) ratio of RO membranes \#1, \#2 and \#3 were 32 gfd $(5.4 \mathrm{~cm} / \mathrm{h}), 41$ gfd $(7.0 \mathrm{~cm} / \mathrm{h})$ and 20 gfd $(3.4 \mathrm{~cm} / \mathrm{h})$, respectively and $0.16,0.20$ and 0.098 , respectively. $\mathrm{NaCl}$ rejection was at least $99 \%$ for all of these RO surfaces. The RO membrane swatches were cut from flat sheet rolls and boiled in nanopure water for $10 \mathrm{~min}$ (according to the manufacturer's instruction, which removed the residual chemicals and any surface contamination and did not change the surface structures and chemistries of these membranes). After cooling to room temperature and prior to using, the membranes swatches were washed several times with nanopure water. The membrane swatches were adhered onto removable polycarbonate coupons (six per reactor) with silicon rubber sealant (Dow Corning, USA). Once the membrane swatches were fixed on the coupons, they were placed in the rotor of the rotating disc reactors (RDR) (Biosurface Technologies Corporation, USA).

The RDR has a variable speed rotating drum, an operating volume of $250 \mathrm{ml}$ and a high surface area to volume ratio. The advantage of these systems is that the fluid conditions can be set and maintained so that the artifacts introduced by varying shear stress or residence time can be eliminated. Fig. 1 illustrates the flow diagram of the reactor setup.

The reactors were fed continuously with Bozeman (Montana, USA) tap water that flows through a granular activated carbon (GAC) column and a biologically activated carbon (BAC) column operated in up-flow mode as a source of indigenous microorganisms. These columns remove the majority of the background carbon from the tap water. Some important water quality parameters (average values) of Bozeman tap water during this study were: alkalinity, $36.09 \mathrm{ppm}$; hardness (total), $59.10 \mathrm{ppm}$; $\mathrm{pH}, 6.5$ to 7.5 ; sulfate, $7.25 \mathrm{ppm}$; iron, $0.02 \mathrm{ppm}$; total dissolved solids, $54.32 \mathrm{ppm}$; turbidity, $0.05 \mathrm{NTU}$; and total organic carbon, 1 to $3 \mathrm{ppm}$. To enhance the growth of biofilm the biologically treated water was amended with nutrients ( $\mathrm{C}: \mathrm{N}: \mathrm{P})$ (glutamic acid, glucose, galactose and arabinose were used for carbon source; $\mathrm{KNO}_{3}$ and $\mathrm{K}_{2} \mathrm{HPO}_{4}$ were used for nitrogen and phosphorous source, respectively). These were added to the reactors at a 100:10:1 (molar ratio) basis $(5.54 \mathrm{ml}$ of carbon source, $16.88 \mathrm{ml}$ of nitrogen source and $4 \mathrm{ml}$ of phosphorus source were added into a 20 - $\mathrm{L}$ container of autoclaved nanopure water).

The rotation speed of the rotor in the RDR was $50 \mathrm{rpm}$ and the hydraulic retention time was $3.5 \mathrm{~h}$ in all reactors. The temperature was ambient $\left(25^{\circ} \mathrm{C}\right)$ and $\mathrm{pH}$ was $7-8$. The reactors were operated continuously for 28 days to ensure satisfactory biofilm growth. The operating conditions and analyses are shown in Table 1. The colony forming units ( $\mathrm{CFU}$ ) in the BAC water were measured using R2A agar (Fisher Scientific, IL). 


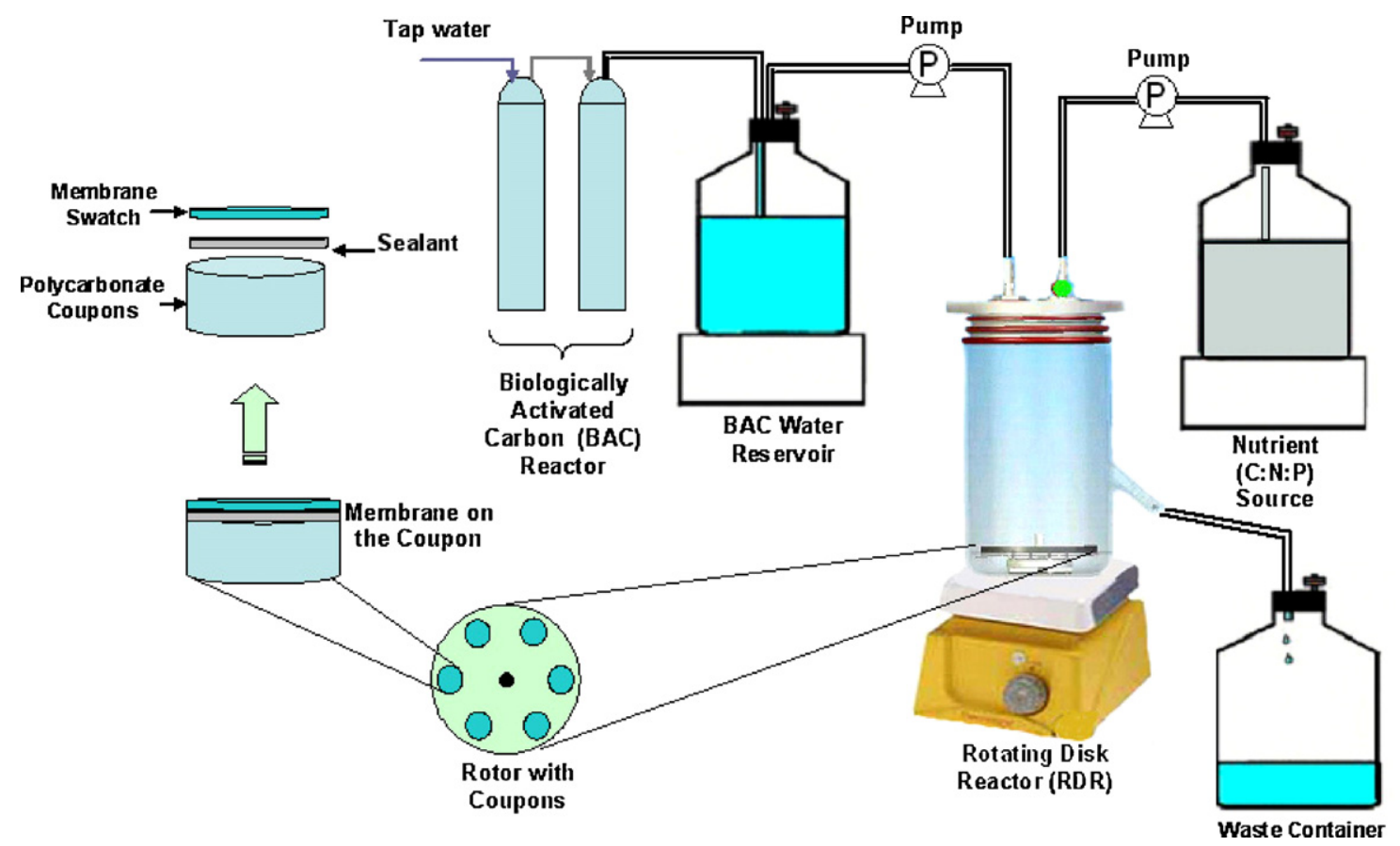

Fig. 1. The schematic of the reactor set-up. The reverse osmosis (RO) swatches are attached to the polycarbonate coupons with silicon rubber sealant.

Membrane swatch sampling was done at the end of the operational period. The membranes were carefully removed from the coupons using a sterilized razor blade and hemostat without disturbing the biofilm. The surfaces with biofoulants were cut into sections with a sterilized scissors for membrane and biofilm assays. For contact angle measurement and X-ray photoelectron spectroscopy (XPS) analysis, the biofoulants were removed from the surfaces of RO membranes with nanopure water and a sterilized soft rubber scrubber (VWR, Denver). Then, the surfaces were dried at room temperature. Prior to removal of biofoulants from RO surfaces, XPS analyses of biofoulants on these surfaces were also performed after drying the membranes with biofilm at room temperature. In our previous study [11], we did not observe any change of surface morphology and chemical compositions during this cleaning procedure of virgin membranes.

Before contact angle and XPS analyses, the RO membrane surfaces were dried again under nitrogen gas for $1 \mathrm{~min}$. Parallel control membranes that had not been subjected to biofouling were also analyzed.

\subsection{Biofilm assays}

Assays of the RO membrane biofoulants included optimized staining and biofilm analysis techniques. For staining live and

Table 1

Operating conditions and parameters of the rotating disk reactors (RDR) with RO membranes \#1, \#2 and \#3.

\begin{tabular}{ll}
\hline Operating conditions & Values and parameters \\
\hline $\begin{array}{l}\text { The period of run } \\
\text { Sampling frequency }\end{array}$ & 28 days \\
Average $\mathrm{CFU} / \mathrm{ml}$ in the biologically & At the end of run \\
activated carbon (BAC) treated water & $(1.41-2.01) \times 10^{4}$ \\
Membrane assays & Images of live/dead cells, \\
& cryo-sectioning, contact angle, \\
& and X-ray photoelectron \\
& spectroscopy $(\mathrm{XPS})$ \\
& $1.5 \mathrm{mg} / \mathrm{L}$ of $\mathrm{C}: 0.18 \mathrm{mg} / \mathrm{L}$ of \\
Nutrient condition (C:N:P) & $\mathrm{N}: 0.04 \mathrm{mg} / \mathrm{L}$ of $\mathrm{P}$ \\
& $42 \%$ of total influent flow rate \\
Flow rate of nutrient & $58 \%$ of total influent flow rate \\
Flow rate of the BAC treated water &
\end{tabular}

dead cells on the surface of RO membranes the LIVE/DEAD BacLight $^{\mathrm{TM}}$ Bacterial Viability Kit for microscopy and quantitative assay (Invitrogen Molecular Probes, Oregon) was used. Equal amounts $(1.5 \mu \mathrm{l} / \mathrm{ml})$ of SYTO $9(3.34 \mathrm{mM})$ and propidium iodide $(20 \mathrm{mM})$ dyes were diluted in $1 \mathrm{ml}$ of nanopure water and after proper dilution and vortexing, dyes were added to the top surface of the membrane and incubated for $1 \mathrm{~h}$ in the dark. After incubation, the excess dye was carefully washed off with nanopure water and the stained cells were observed under the epifluorescence microscope (Nikon, Eclipse E 800, Japan) with a 100× objective. 15-20 images of live and dead cells in the top layer of biofilm on the RO surfaces were captured and analyzed with MetaMorph software (Molecular Devices Corporation, USA).

In addition, for the cryo-sectioning, the RO membranes with biofoulants were stained with LIVE/DEAD BacLight ${ }^{\mathrm{TM}}$ Bacterial Viability Kit without disturbing the biofilm following the same procedures as for the live/dead imaging. After washing off the excess dye with nanopure water, biofoulants on the top of membranes were frozen within 2-3 min after being flooded with the optimum cutting temperature (OCT) liquid (Sakura Finetek USA, CA) keeping the inactive membrane surfaces (which were used to adhere onto the coupon) on a metal plate over a dry-ice block. A cryostat (Leica CM 1850, Germany) was used to cut sections through the biofilm of $5.0 \mu \mathrm{m}$. The sectioned layer of the biofoulants and membranes was placed on a positively charged microscope slide (Fisher Scientific, IL) and observed under the epifluorescence microscope with a $20 \times$ objective. The cryo-sections of stained biofilms on membranes were analyzed with MetaMorph software to calculate the regions of live/dead cells and the thickness of accumulated biofoulants on the membrane surfaces. Each image has a distribution of live (green) and dead (red) cells along the thickness of biofilm on the membrane.

A line scan was done with the MetaMorph software across the slices of membranes with biofoulants. Each line scan generated two profiles depending on the location of live and dead cells trapped inside the biofilms. To calculate the thickness of live and dead cell regions, the width at the mid-height of each distribution was measured. Using the width at mid-height of each profile, the software calculated the relative thickness of each profile in terms of live and 

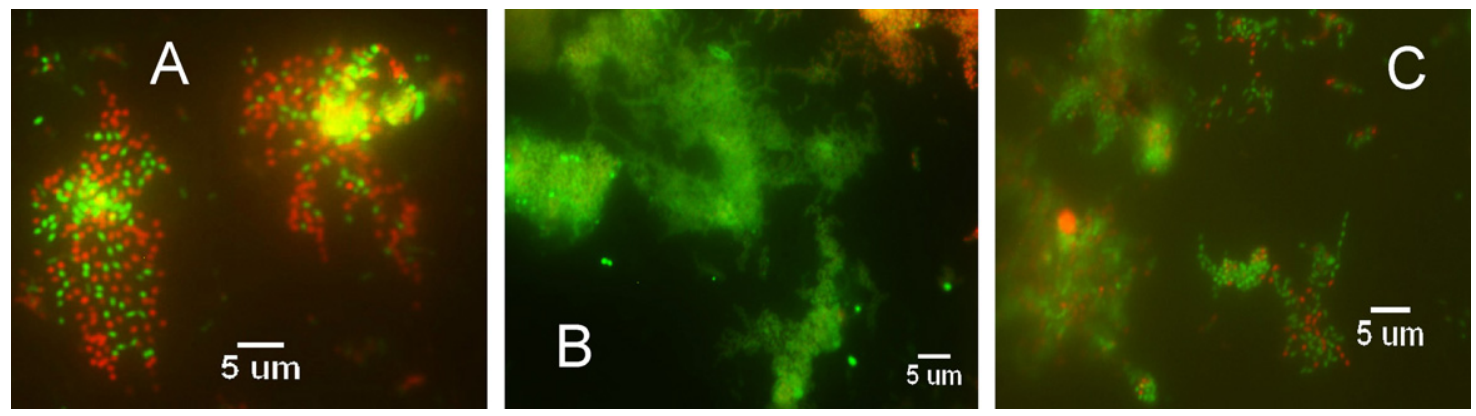

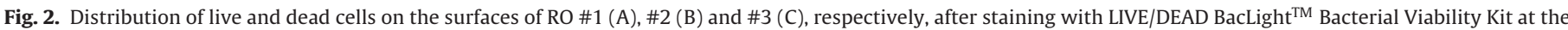
end of operational period on Day 28.

dead cell regions. For each membrane swatch, 10-15 slices of membranes were imaged (three images per slice) and from each image, five different line-scans were generated for analysis.

\subsection{Membrane assays}

Contact angles, the direct measurement of surface hydrophobicity, were determined by the sessile drop method using a Rame'-Hart contact angle goniometer (Model 100-22). 1-2 $\mu$ l of nanopure water was introduced onto the clean and air dried membrane surface (by a Gilmont (IL) microsyringe with a droplet diameter of $0.4-0.5 \mathrm{~cm}$ ). $10-15$ different measurements of contact angles (advanced and receding angles) were carried out for each piece of physically cleaned of biofouled surface and its respective virgin membrane surface.

XPS analyses of RO membranes were done on the virgin surfaces and also before and after cleaning of biofoulants to characterize the change of mass percentage of surface chemical elements due to the formation of biofoulants and their interactions. Biofoulants on the RO surfaces were dried in room temperature prior to analysis. A 5400 PHI ESCA spectrometer (Physical Electronics, Eden Prarie, MN) with a non-monochromated aluminum $\mathrm{K} \alpha \mathrm{X}$-ray source $(h v=1486.6 \mathrm{eV})$ at a power of $250 \mathrm{~W}$ was used for the analysis. Acceleration voltage was $15 \mathrm{kV}$ and current was 12-18 mA. The second and fourth derivatives of the spectrum were inspected to locate the positions of various peaks. The core level peaks were then successfully fitted with component peaks with a Gaussian-Lorentzian distribution. At these operating conditions, the penetration depth was approximately $10 \mathrm{~nm}$ and the spot size analyzed was approximately $300 \mu \mathrm{m} \times 700 \mu \mathrm{m}$.

\section{Results and discussion}

This study with three different types of aromatic polyamide thin-film RO surfaces without filtration provides an example of how RO surface associated modified characteristics affect biofouling formation and the subsequent effects of biofilm on physical and chemical properties of RO surfaces, which was independent from the initial membrane productivity. Each type of analysis will be discussed below.

\subsection{Visualization and quantitative comparisons of biofouling formation, structure and control by three different biofouling resistant polyamide $R O$ surfaces}

\subsubsection{Live and dead cells in the biofoulants on the RO surfaces}

It appears that the distribution of heterogeneous characteristics of RO surfaces, most likely characterized by the presence of unevenly distributed surface modifications, defines the region of biofouling accumulation. Fig. 2 shows the orientation of the live and dead cells as viewed from the top surface of the biofoulants on the RO surfaces. During this study, more than $90 \%$ of cells in the BAC water (RDR influent) were determined to be alive after staining with LIVE/DEAD BacLight ${ }^{\mathrm{TM}}$ Bacterial Viability Kit (data not shown). The relative number of total cells (both live and dead) was lower on RO \#1 membrane compared to that on RO \#2. There were more dead cells (red) than live cells (green) on RO \#1. The RO \#2 membrane surface was characterized by a distribution of substantial amount of cells that covered the entire surface in clusters and most of them appeared to be alive. The relative number of cells on RO \#3 was intermediate to RO \#1 and RO \#2 and that of live and dead cells on RO \#3 was similar.

Using different approaches in filtration mode, Ridgway et al. [41] and Subramani and Hoek [34] reported that individual cells were deposited at discrete locations on the membrane surface and later, new cells deposited at the leading stagnation points created by previously attached cells. Furthermore, initial foulant deposition on the membrane surface was controlled by interactions between the bulk foulants, organic material and the membrane surface [42]. The biofoulants on these surfaces were not evenly distributed which suggests that there were heterogeneities on the RO surfaces that controlled the accumulation of cells or biofouling. Ideally, this would provide more capacity for filtration when the membranes are used under typical filtration conditions. As stated in the methods section, the initial membrane productivity of RO \#2 was the highest; however, the number of cells accumulated on this surface was also the highest. Sagle et al. [29] reported that coating thickness of antifouling agents resulted in significant differences in water flux even between samples coated with the same coating materials. Interestingly, the addition of extra aliphatic groups on the polyamide layer increased the membrane initial productivity of RO \#2, which was reduced in the case of RO \#3 most likely because of extra aromatic groups on the polyamide layer. There was no apparent relationship between the distribution of biofouling on the surface and overall membrane initial productivity, which suggests that during the development of RO membranes both parameters should be considered.

Furthermore, Norberg et al. [43] showed that the chemical compatibility of membrane surfaces should be carefully considered in the process of developing fouling resistant membranes. The extent of RO surface associated biocidal penetration inside the biofilm layer defines the number of live and dead cells within the biofilm; however, some particle-associated bacteria display antagonistic activities towards other bacteria [44], which suggest that inhibition among attached bacteria in a biofilm can also affect the development of microbial communities and EPS production on a surface [45].

\subsubsection{Biofoulant thickness parameters}

A novel approach, cryo-sectioning, was used to determine the thickness of RO biofoulants. Fig. 3(A), (C) and (E) shows representative cryo-sectioned images of biofoulants on RO \#1, \#2, and \#3 

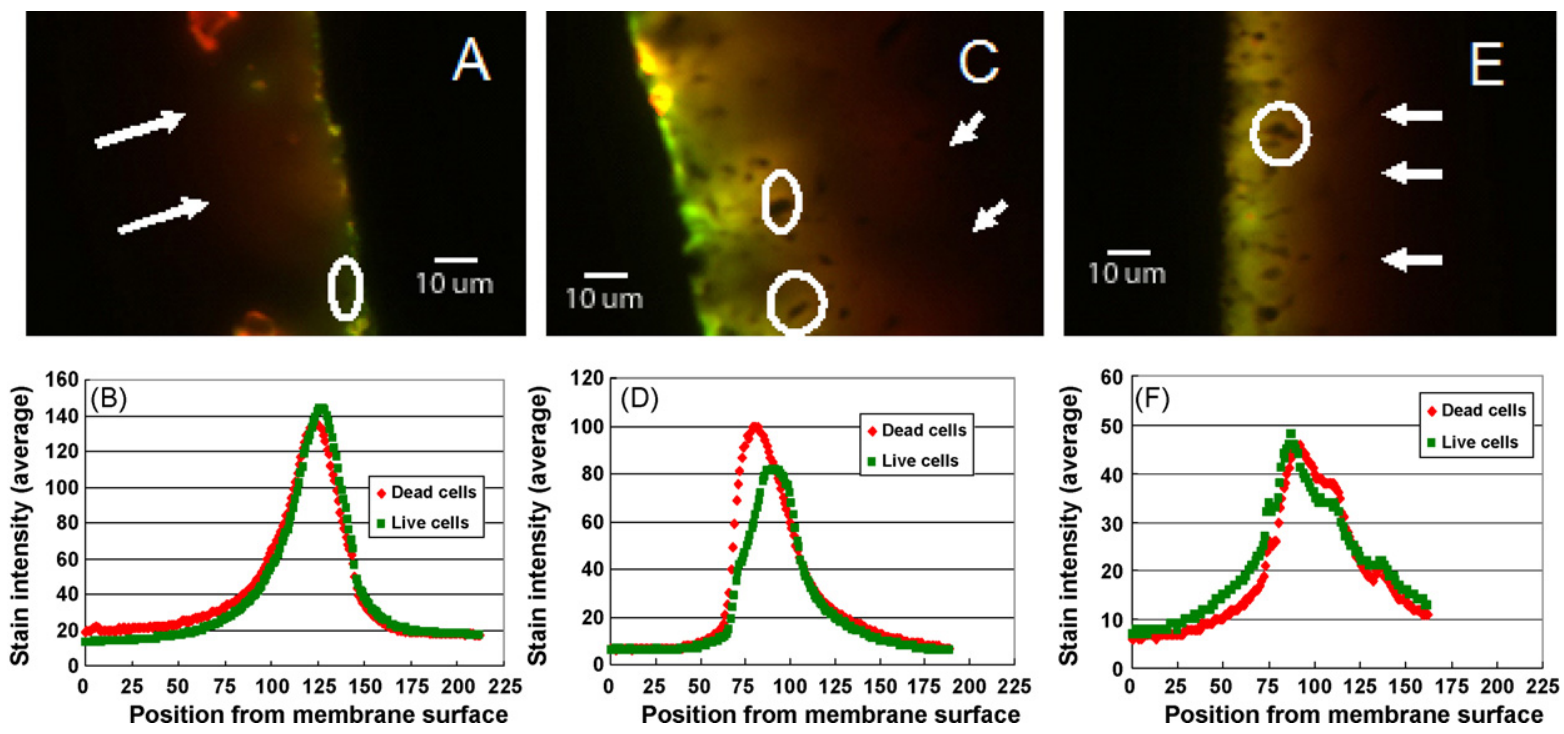

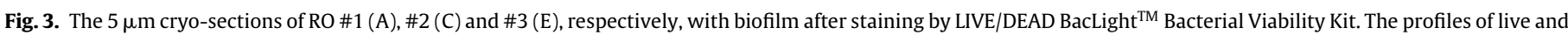

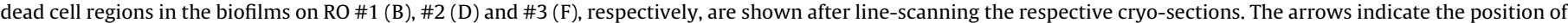
membrane under the biofilm and circles show the hollow pockets inside the biofoulant.

membranes, respectively. The arrows indicate the position of membranes underneath the biofouling. Due to shear, it was anticipated that the overall biofilm thickness will not increase indefinitely. The effectiveness of the biofouling resistant RO surfaces depends on the chemistry and heterogeneity of surface modifications. It was evident that most of the cells nearest to the membrane were dead and cells in the top regions are mostly alive. These images also suggest that the surface modification was unevenly and heterogeneously distributed on the RO surfaces. The biofoulants on the RO surfaces were not formed in a compact layer. Clusters of cells (live and/or dead) with hollow pockets were noticed (Fig. 3(A), (C) and $(E)$ ), which indicates the spatial variation of porosity inside the biofilm on the surfaces [46] that ultimately causes the spatial distribution of diffusivity of influent through the biofoulants on the membrane surfaces. Distribution of live vs dead cells is also important for assessing the long-term heterogeneity of the biofilm. The hydrolytic enzyme activities of attached live bacteria [47] may help liberate EPS from the biofilm. Conversely, once the bacteria attached to the surface are dead, they can no longer produce EPS $[48,49]$, which will increase the effective diffusivity within the biofilm [50], especially near the surfaces.

These observations are subjective, so line scans of these images were created to produce profiles of live and dead cells within the biofilm along each scan. Fig. 3(B), (D) and (F) shows the profiles of live and dead cells along three sections of representative biofoulant slices. The skewness and intensity of the distributions of live and cell regions depend on the number of live and dead cells along the section of biofilm, which will vary from one section to another and probably depends on the surface morphology and properties of membrane [4]. Moreover, there could be a vertical profile of biomass density inside the biofoulants possibly due to the presence of microcolonies separated by interstitial voids or due to the spatial distribution of physiological groups of microorganisms producing different polymers [50].

The peaks of staining intensity of the live cell regions on RO \#1 and \#2 were closer to the biofilm-fluid interface than that of dead cells, which indicates that the dead cells were located more towards the membrane surfaces and the live cells were located more towards the top surface of the biofilm. The peaks of staining intensity of live and dead cell regions on RO \#3 were opposite from the other membranes. The peaks of staining intensities of the dead and live cell regions inside the biofoulants on RO \#1, \#2 and \#3 surfaces were separated by 2.1 to $2.9 \mu \mathrm{m}, 2.3$ to $7.4 \mu \mathrm{m}$ and 1.6 to $3.1 \mu \mathrm{m}$, respectively. This suggests that the extra aromatic groups on the polyamide layer of RO \#3 surface penetrated further into the biofilm than that of other RO surfaces. Furthermore, Schneider et al. [18] observed that different surface chemistries defined the RO membrane biofoulant thickness, which also controlled the membrane productivity during filtration.

Fig. 4 shows the average relative thickness of live and dead cell regions. The standard errors of mean values of these thicknesses (10-15 slices of membranes were imaged (three images per slice) and from each image, five different line-scans were generated for analysis) were relatively small $(0.98-1.91 \mu \mathrm{m})$. These data support qualitative staining information in Fig. 2 where it was shown that RO \#2 had the thicker layer of biofouling, and RO \#1 and RO \#3 were comparable. These data support the observations of Hirose et al. [51] and Schneider et al. [18], which showed that the accumulation of biofoulants depended on the surface properties of the RO membranes.

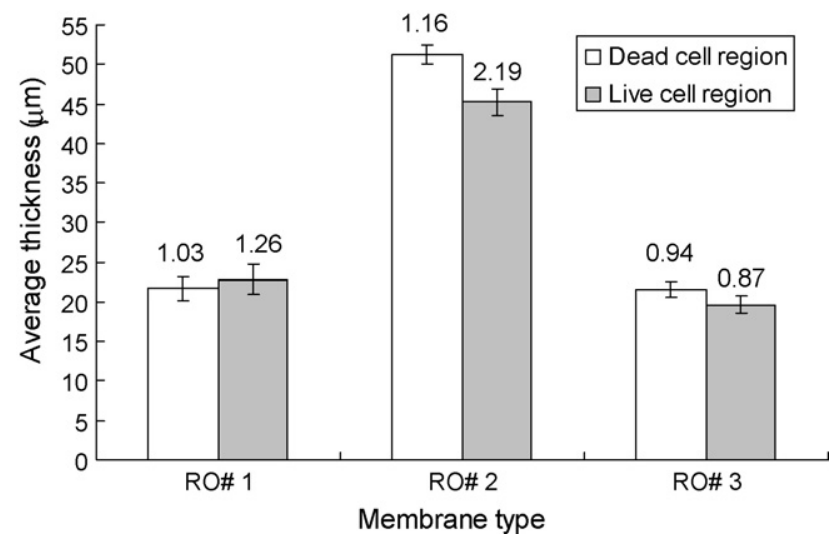

Fig. 4. Average thickness of live and dead cell regions in the biofoulants on the surfaces of RO membranes at the end of operational period on Day 28. Error bars show the \pm standard error of mean, which varied from 0.98 to $1.91 \mu \mathrm{m}$. The values on the bar of each live and dead cell regions show the average accumulation rate ( $\mu \mathrm{m} /$ day) of live and dead cell regions in the biofoulants on the membranes. 

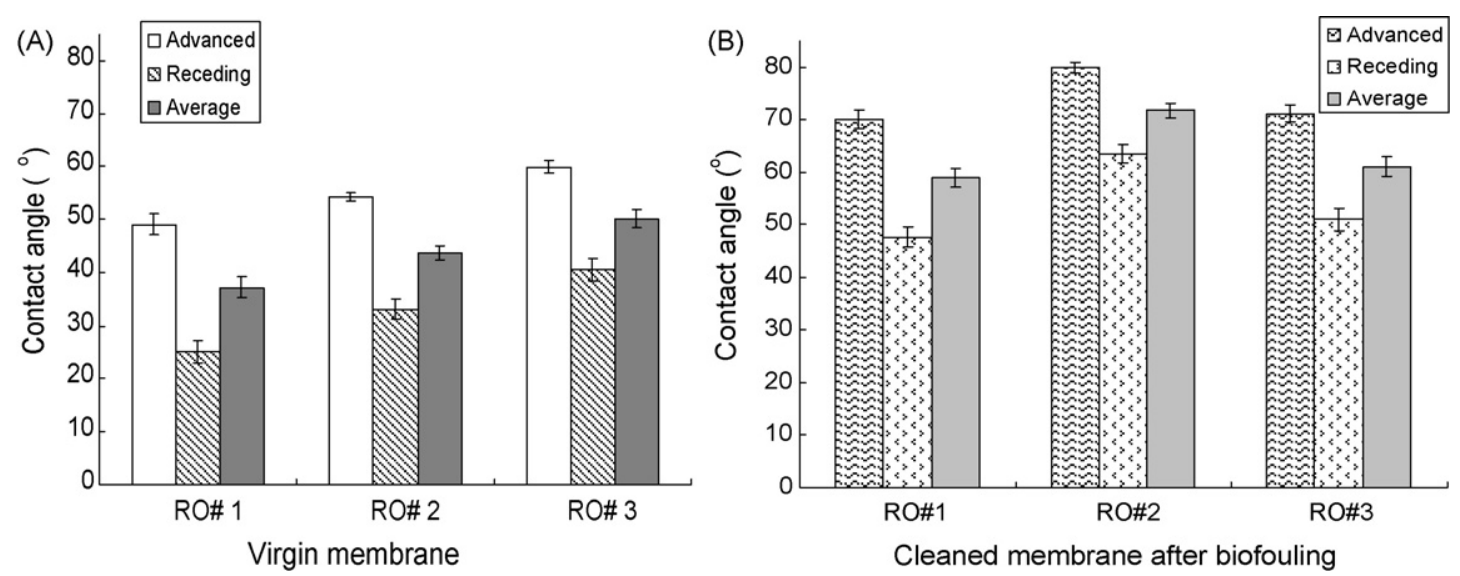

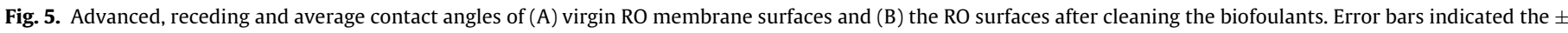
standard error of means of these estimations, which varied from 0.86 to $2.21^{\circ}$.

Ideally, these measurements would be made with multiple membranes over a period of several days when biofouling was developing on the membranes. In this experiment, only one time point at 28 days was analyzed. Regardless of the limitation of one end-point sample, relative comparisons of accumulation rate can be made. The average accumulation rate of the biofoulants on the RO \#3 was the lowest, although it is difficult to state that they are substantially different than those on RO \#1. In contrast, the rate for $\mathrm{RO} \# 2$ was double than that of the other membranes.

Based on the RO biofoulant parameters-live/dead cell images, the cyro-section images, the line scans, the average thicknesses and the relative accumulation rates, comparisons between the membranes can be made, and the best "performance" was seen with RO \#1 and \#3; however, the membrane productivity of RO \#2 was the highest. The addition of aliphatic groups on the polyamide layer of RO \#2 was not effective in reducing biofilm accumulation and thickness.

This observation suggests that during the development of best biofouling resistant surfaces, the RO surface chemistries should ensure both biofouling resistant properties and higher membrane productivity.

\subsection{Estimation and correlation of the biofilm parameters with} the change of hydrophobicity and surface chemical compositions

\subsubsection{RO surface hydrophobicity changes due to biofouling}

Contact angle is a direct measure of surface hydrophobicity of a dry surface. Fig. 5(A) and (B) shows the contact angles (advanced, receding and average of advanced and receding angles) of the virgin membranes and biofouled surfaces after cleaning, respectively. The hydrophobicity of the RO membranes increased from $12^{\circ}$ to $32^{\circ}$ from their virgin conditions, which indicates the ultimate loss of membrane permeability due to the attached biofouling macromolecules and suggests inadequate cleaning of biofoulants from the RO surfaces. The contact angle increase was the lowest for RO \#3 $\left(\sim 12^{\circ}\right)$ and that for RO \#2 was the highest $\left(\sim 32^{\circ}\right)$. Both RO \#1 and RO \#3 surfaces had similar hydrophobicities after exposure to biofoulants and cleaning. The contact angle measurements support earlier observations that RO membranes \#1 and \#3 were less influenced by biofouling than $\mathrm{RO} \# 2$.

In addition, it must be noted that contact angle measurement of RO surfaces does not provide specific information of biofouling control potentials. Several studies have shown that abundance of bacteria have significant impacts on biofilm characteristics, such as biomass area, relative hydrophobicity, surface charge, floc structure and so on $[52,53]$. Initial hydrophobicity of RO \#1 and RO \#3 are the lowest and highest (Fig. 5A), respectively; however, average biofoulant thickness on these surfaces are almost same and less than that on RO \#2 (Fig. 4). RO \# 2 has initial hydrophobicity higher than RO \#1 and lower than RO \#3 (Fig. 5A).

Park et al. [54] conducted a study with polyamide RO surfaces without biofouling controlling capability and found that more hydrophobic RO surfaces had more attached cells. In our another study [55] using self-assembled monolayers (SAMs) surfaces with varied hydrophobicity, ammonia oxidizing and heterotrophic bacteria showed more attachment to high hydrophobic surfaces. In this study, the relative number of cells on RO \#2 was the highest (Fig. 2B); however, hydrophobicity of virgin RO \#2 was not the highest (Fig. 5A). It is likely that the heterogeneity of the surface modifications and the aromatic nature of RO \#1 and RO \#3 surfaces played a key role controlling the biofilm thickness and number of cells on the surfaces. Furthermore, both electrostatic and hydrophobic interactions of RO surfaces appear to play a role in membrane fouling [29]. The surface with the least capacity for biofouling control (RO \#2 containing aliphatic groups) had the highest initial membrane productivity, but it also suffered the greatest change in hydrophobicity due to biofouling, which will ultimately cause flux decline.

The initial hydrophobicity of RO \#2 was greater than that of RO \#1, but after exposure to biofouling the increase in RO \#2 hydrophobicity exceeded that of other membranes. This suggests that the differences in biofouling control, membrane productivity and virgin membrane hydrophobicity are independent membrane properties. During membrane formation, optimum combinations of these parameters would lead to highly efficient surfaces for the filtration, which was demonstrated by this study for RO \#1. It is important to note that during filtration, once the biofoulants form on the RO surfaces, initial membrane productivity cannot be restored even after chemical [56] and concentrated salt [57] cleaning of biofouled surfaces. However, the initial membrane productivity is an important parameter during selection of highflux membrane surfaces. This study without filtration also shows that after biofouling, the RO surface hydrophobicities increased; however, this increment of hydrophobicity would be different if the study was performed in filtration mode. This is the first report which states that the extra addition of aliphatic hydrocarbon groups on the polyamide surface of RO membrane ( $R O \# 2$ ) suffered higher biofouling accumulations than aromatic groups.

\subsubsection{Impact of biofoulants on RO surface chemical compositions}

Representative XPS plot of RO \#1 surface at virgin condition and that after removal of the biofoulants are shown in Fig. 6. It is interesting to note that along with biofilm accumulations, inorganic accumulations or the changes of mass percentage of chemical 

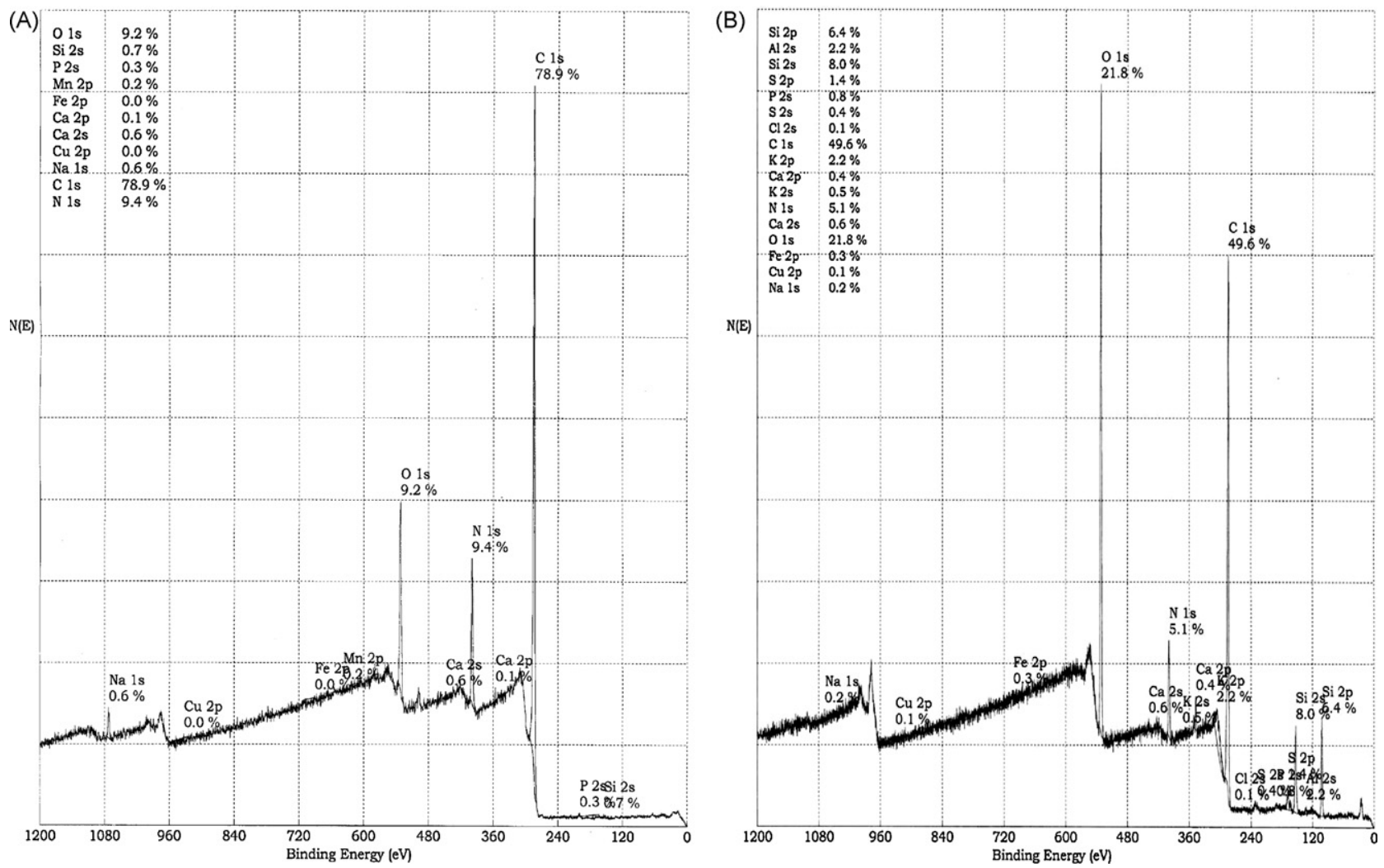

Fig. 6. X-ray photoelectron spectroscopy (XPS) plots of (A) virgin and (B) after physical cleaning of biofoulants from RO \#1 surface.

elements on the RO surfaces were also seen. Table 2 illustrates the mass percentages of important chemical elements obtained from XPS analyses on all three RO surfaces before and after cleaning of biofoulants as well as in virgin conditions. The increases in calcium, aluminum and silica could be due to the particulate fouling included in the biofilm or the formation of calcium aluminum silicates, which was not clear from this study.

The BAC treated water could have contained trace amounts of chlorine, which appeared on the membrane surface after biofouling formation. Once the membranes are exposed to nutrients and bacteria as well as their associated byproducts, the carbon (C) content on the surface was reduced to 10-35\%. However, the amount of nitrogen $(\mathrm{N})$ and oxygen $(\mathrm{O})$ decreased and increased, respectively. The $\mathrm{O}$ increase and $\mathrm{C}$ decrease could be the presence of EPS, which have high $\mathrm{O}$ to $\mathrm{C}$ ratios $(\mathrm{O} / \mathrm{C})$. After cleaning the RO surfaces, the $\mathrm{O} / \mathrm{C}$ on RO \#1 and RO \#3 were almost the same $(\sim 0.44)$; however, this ratio on $\mathrm{RO} \# 2$ was the lowest (0.28). These values suggest that the accumulations of EPS on RO surfaces was higher in the presence of aromatic groups and lower because of aliphatic groups on the top polyamide layer of RO surfaces. The presence of aliphatic groups reduced the EPS accumulation, but increased the number of cells (Fig. 2B).

Bacteria inside the biofoulants attached to the membrane surface produce proteins, polysaccharides, and other types of organic materials. Both colloidal and non-colloidal hydrophilic organic materials have high affinity and potential interactions with polyamide membrane surfaces and therefore, change the chemical compositions of those surfaces [58]. Moreover, depending on the feed water quality to the RO system, changes of membrane surface chemical compositions vary [59]. These changes will result in permanent flux loss at the end of operation and after repeated cleaning [39].

Table 2

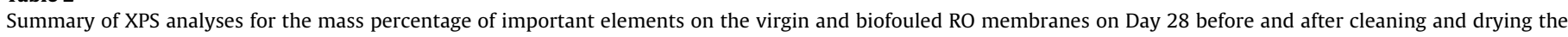
surfaces.

\begin{tabular}{|c|c|c|c|c|c|c|c|c|c|c|}
\hline & \multicolumn{10}{|c|}{ Important elements (\%) } \\
\hline & $\mathrm{C} 1 \mathrm{~s}$ & $01 \mathrm{~s}$ & $\mathrm{~N} 1 \mathrm{~s}$ & P 2s & S 2p & Si $2 p$ & Si $2 s$ & $\mathrm{Al} \mathrm{2s}$ & Ca $2 p$ & $\mathrm{Cl} 2 \mathrm{~s}$ \\
\hline \multicolumn{11}{|l|}{ RO \# 1} \\
\hline Virgin & 78.9 & 9.2 & 9.4 & 0.3 & 0 & 0 & 0.7 & 0 & 0.1 & 0 \\
\hline Day 28 (with biofoulants) & 48.7 & 23.7 & 4.0 & 0.3 & 1.6 & 7.9 & 9.2 & 2.5 & 0.2 & 0.1 \\
\hline Day 28 (after cleaning) & 49.6 & 21.8 & 5.1 & 0.8 & 1.4 & 6.4 & 8 & 2.2 & 0.6 & 0.1 \\
\hline \multicolumn{11}{|l|}{ RO \# 2} \\
\hline Virgin & 71.6 & 12.2 & 8.3 & 0.4 & 0.5 & 0.3 & 0 & 0 & 0.4 & 0 \\
\hline Day 28 (with biofoulants) & 48.4 & 23.3 & 4.3 & 0.2 & 0.8 & 7.9 & 9.6 & 1.9 & 0.2 & 0.3 \\
\hline \multirow[t]{2}{*}{ Day 28 (after cleaning) } & 60.6 & 17 & 5.6 & 0.3 & 1.3 & 1.4 & 8.6 & 1.2 & 0.3 & 0.2 \\
\hline & & & & & & & & & & RO\#3 \\
\hline Virgin & 79.9 & 10.5 & 10.3 & 0.5 & 0.1 & 0.2 & 0 & 0 & 0.1 & 0 \\
\hline Day 28 (with biofoulants) & 50.6 & 29.5 & 5.8 & 0.6 & 1.1 & 6.5 & 7.1 & 0.8 & 0.6 & 0.3 \\
\hline Day 28 (after cleaning) & 47.6 & 21.3 & 5.5 & 0.7 & 0 & 8.9 & 10.2 & 2.6 & 0.3 & 0.2 \\
\hline
\end{tabular}


The $\mathrm{O}$ and $\mathrm{N}$ mass percentage ratios for all virgin aromatic polyamide RO surfaces were greater than unity and $\sim 1$. This ratio was $\sim 4$ times higher for RO \#1 and RO \#3 after cleaning the biofoulants and $\sim 3$ times higher for RO \#2. These significant changes of the $\mathrm{O}$ and $\mathrm{N}$ mass percentage ratios were likely due to the interaction of different macromolecules in biofoulants with the RO surfaces [60]. It is important to note that the penetration depth of XPS was $\sim 10 \mathrm{~nm}$ [61] and the mass percentage values of chemical elements in Table 2 for the virgin membranes are near and within the surface modifications, while that for biofouled surfaces are within the foulants. These chemical elements for cleaned RO surfaces may also include the biofoulants and the top layer of the RO surfaces. It is evident from this analysis that biofouling changed the surface chemical compositions in the top layer of these RO membranes and there was no effect of biofouling on the bottom aromatic polyamide layer and other layers (polysulfone and polyester).

The feed compositions to these three reactors were identical; however, the mass percentage of chemical elements on the top of biofoulants of RO \#1 and RO \#2 are very similar and the major elements, e.g. C, O, N and phosphorous (P), in these cases are less than that on RO \#3. This observation also supports that the activity of surface modification on $\mathrm{RO} \# 3$ penetrated more inside the biofoulants (Fig. 3F) than that on RO \#1 and RO \#2 and subsequently disinfected/killed more cells on the top layer of biofoulants and made this changes of major chemical elements.

It is therefore important that RO membranes should be sufficiently cleaned so that their virgin membrane chemistries can be retained after repeated cycles of operation. Moreover, other researchers $[38,62]$ reported that chemical cleaning of foulants should be optimized to minimize the change of surface chemical structure of the membranes. In this context, RO \#2 had the best surface chemical stability even though it had the worst performance relative to the accumulation of biofouling and hydrophobicity changes. This finding also supports that the stability of surface chemical composition during fouling is an important parameter for higher membrane productivity.

\section{Conclusions}

The application of RO membrane filtration in advanced water and wastewater reclamation has increased as a result of the development of more sustainable membrane technologies, which has lowered the cost of membrane modules and produced higher quality filtrate. To reduce the cost of operations, membrane manufacturers are developing RO membranes with various functional properties that are productive at low pressures and are also less susceptible to biofouling. To adequately test these new surfaces, it is necessary to correlate biofouling and its parameters and impact on the RO surface with membrane productivity. The approach presented in this manuscript provides a comprehensive combination of novel mechanisms. The suite of analyses gives comparative information that can be compared so that the choices for further membrane testing and evaluation can be based on several measures of membrane performance rather than relying primarily on membrane initial productivity.

As seen with the three membranes that were tested, differences in surface properties of the membranes contributed to variations in biofilm formation and the proportion of live and dead cells. Biofouling changed the surface hydrophobicity as well as chemical elements. The extent of surface modification penetration to the biofoulants defines the number of live and dead cells inside the biofilm. Effective disinfection of cells inside the biofilm caused more hollow regions providing more space for diffusivity. Based on this study we suggest that during biofouling resistant polyamide RO membrane formation, several issues should be considered equally: membrane productivity, heterogeneity of anti-biofouling agents on the membrane surface, stability of surface chemical elements, and role of virgin RO surface hydrophobicity. Based on our data, it appears that the commercially available RO \#1 (FilmTec's BW30) had the greatest potential for controlling biofouling among these three RO surfaces tested in this study. Surprisingly, we found that the addition of aliphatic hydrocarbon groups on the polyamide layer of RO membranes increased the biofouling compared to adding aromatic groups. Although the analyses described here are somewhat simplistic, they provide one approach towards understanding biofilm formation, biofouling and their impact on the RO surfaces. They can also be used in further investigations where the membranes are tested in filtration mode.

\section{Acknowledgements}

This research was supported by the FilmTec Corporation, a subsidiary of the Dow Chemical Company.

\section{References}

[1] S. Belfer, J. Gilron, N. Daltrophe, Y. Oren, Comparative study of biofouling of NF modified membrane at SHAFDAN, Desalination 184 (2005) 13-21.

[2] H. Ivnitsky, I. Katz, D. Minz, E. Shimoni, Y. Chen, J. Tarchitzky, R. Semiat, C.G. Dosoretz, Characterization of membrane biofouling in nanofiltration processes of wastewater treatment, Desalination 185 (2005) 255-268.

[3] K.L. Chen, L. Song, S.L. Ong, W.J. Ng, The development of membrane fouling in full-scale RO processes, J. Membr. Sci. 232 (2004) 63-72.

[4] M.Al-Ahmed, F.A. Abdul Aleem, A. Mutiri, A. Ubaisy, Biofouling in RO membrane systems Part 1: Fundamentals and control, Desalination 132 (2000) 173-179.

[5] J.S. Vrouwenvelder, D. van der Kooij, Diagnosis, prediction and prevention of biofouling of NF and RO membranes, Desalination 139 (2001) 65-71.

[6] J.S Vrouwenvelder, J.W.N.M. Kappelhof, S.G.J. Heijman, J.C. Schippers, D. van der Kooij, Tools for fouling diagnosis of NF and RO membranes and assessment of the fouling potential of feed water, Desalination 157 (2003) 361-365.

[7] E. Huertas, M. Herzberg, G. Oron, M. Elimelech, Influence of biofouling on boron removal by nanofiltration and reverse osmosis membranes, J. Membr. Sci. 318 (2008) 264-270

[8] M.R. Wlesner, P. Aptel, Mass transport and permeate flux and fouling in pressure-driven membrane processes, in: J. Mallevialle, P.E. Odendaal, M.R. Wiesner (Eds.), Water Treatment Membrane Processes, McGraw-Hill, New York, 1996, pp. 4.1-4.30.

[9] T.F. Speth, A.M. Gusses, R.S. Summers, Evaluation of nanofiltration pretreatments for flux loss control, Desalination 130 (2000) 31.

[10] S.Y. Kwak, D.W. Ihm, Use of atomic force microscopy and solid-state NMR spectroscopy to characterize structure property-performance correlation in high-flux reverse osmosis (RO) membranes, J. Membr. Sci. 158 (1999) 143-153.

[11] M.M.T. Khan, B. Mickols, D.J. Moll, J. Niu, A.K. Camper, Heterogeneity and Distribution of Biofilm on Reverse Osmosis and Nanofiltration Membranes in Rotating Disk Reactor System, North American Membrane Society (NAMS) conference in Chicago, USA, 2006, pp. 12-17.

[12] H.F. Ridgway, H.C. Flemming, Membrane biofouling, in: J. Mallevialle, P.E. Odendaal, M.R. Wiesner(Eds.), Water Treatment Membrane Processes, McGraw-Hill, 1996, pp. 6.1-6.62.

[13] M. Herzberg, S. Kang, M. Elimelech, Role of extracellular polymeric substances (EPS) in biofouling of reverse osmosis membranes, Envrion. Sci. Technol. 43 (2009) 4393-4398

[14] H.C. Flemming, Reverse osmosis membrane biofouling, Exp. Therm. Fluid Sci. 14 (1997) 382-391.

[15] N.Jang, X. Ren, G. Kim, C. Ahn, J. Cho, I.S. Kim, Characteristics of soluble microbial products and extracellular polymeric substances in the membrane bioreactor for water reuse, Desalination 202 (2007) 90-98.

[16] H.C. Flemming, Biofouling in water systems-cases, causes and countermeasures, Appl. Microbiol. Biotechnol. 59 (2002) 629.

[17] W.G. Characklis, K.C. Marshall, Biofilms, John Wiley \& Sons, 1990.

[18] R.P. Schneider, L.M. Ferreira, P. Binder, E.M. Bejarano, K.P. Goes, E. Slongo, C.R. Machado, G.M.Z. Rosa, Dynamics of organic carbon and of bacterial populations in a conventional pretreatment train of a reverse osmosis unit experiencing severe biofouling, J. Membr. Sci. 266 (2005) 18-29.

[19] J.Y. Hu, L.F. Song, S.L. Ong, E.T. Phua, W.J. Ng, Biofiltration pretreatment for reverse osmosis (RO) membrane in a water reclamation system, Chemosphere 59 (2005) 127-133.

[20] L.E. Applegate, C.W. Erkenbrecher, H. Winters, New chlorination process to control after growth and biofouling in Permasep B-10 RO surface seawate plants, Desalination 74 (1989) 51-67.

[21] J.S. Louie, I. Pinnau, I. Ciobanu, K.P. Ishida, A. Ng, M. Reinhard, Effects of polyether-polyamide block copolymer coating on performance and fouling of reverse osmosis membranes, J. Membr. Sci. 280 (2006) 762-770. 
[22] H. Ju, B.D. McCloskey, A.C. Sagle, Y.H. Wu, V.A. Kusuma, B.D. Freeman, Crosslinked poly(ethylene oxide) fouling resistant coating materials for oil/water separation, J. Membr. Sci. 307 (2008) 260-267.

[23] C.W. Michelle, P. John, Z. Andrew, Bench-scale testing of surfactantmodified reverse osmosis/nanofiltration membranes, Desalination 115 (1998) 15-32.

[24] S. Belfer, Y. Purinson, R. Fainshtein, Y. Radchenko, O. Kedem, Surface modification of commercial composite polyamide reverse osmosis membranes, J. Membr. Sci. 139 (1998) 175-181.

[25] A.-F. Che, F.-Q. Nie, X.-D. Huang, Z.-K. Xu, K. Yao, Acrylonitrile-based copolymer membranes containing reactive groups: surface modification by the immobilization of biomacromolecules, Polymer 46 (2005) 1106011065.

[26] V. Thom, K. Jankvoa, M. Ulbricht, J. Kops, G. Jonsson, Synthesis of photoreactive a-4-azidobenzoyl- $\omega$-methoxy-poly(ethylene glycol)s and their end-on photografting onto polysulfone ultrafiltration membranes, Macromol. Chem. Phys. 199 (1998) 2723-2729.

[27] J. Wang, C.J. Pan, N. Huang, H. Sun, P. Yang, Y.X. Leng, J.Y. Chen, G.J. Wan, P.K. Chu, Surface characterization and blood compatibility of poly(ethylene terephthalate) modified by plasma surface grafting, Surf. Coat. Technol. 196 (2005) 307-311.

[28] G. Kang, M. Liu, B. Lin, Y. Cao, Q. Yuan, A novel method of surface modification on thin-film composite reverse osmosis membrane by grafting poly(ethylene glycol), Polymer 48 (2007) 1165-1170.

[29] A.C. Sagle, E.M. vanWagner, H. Ju, B.D. McCloskey, B.D. Freeman, M.M. Sharma, PEG-coated reverse osmosis membranes: desalination properties and fouling resistance, J. Membr. Sci. 340 (2009) 92-108.

[30] C.J. Gabelich, T.I. Yun, B.M. Coffey, I.H. Suffet, Effects of aluminium sulfate and ferric chloride coagulant residuals on polyamide membrane performance, Desalination 150 (2002) 15.

[31] T.T. Nielsen, U.C. Brinch, P.C. Ragas, J.B. Andersen, C.S. Jacobsen, S. Molin, Development and dynamics of Pseudomonas sp. Biofilms, J. Bacteriol. 182 (2000) 6482-6489.

[32] C.M. Pang, P. Hong, H. Guo, W.T. Liu, Biofilm formation characteristics of bacterial isolates retrieved from a reverse osmosis membrane, Environ. Sci. Technol. 39 (2005) 7541-7550.

[33] M. Herzberg, M. Elimelech, Physiology and genetic traits of reverse osmosis membrane biofilms: a case study with Pseudomonas aeruginos, ISME J. 2 (2008) 180-194.

[34] A. Subramani, E.M.V. Hoek, Direct observation of initial microbial deposition onto reverse osmosis and nanofiltration membranes, J. Membr. Sci. 319 (2008) 111-125.

[35] K.C. Khulbe, T. Matsuura, Characterization of synthetic membranes by Raman spectroscopy, electron spin resonance and atomic force microscopy: a review, Polymer 41 (2000) 1917-1935.

[36] T. Knoell, J. Safarik, T. Cormack, R. Riley, S.W. Lin, H. Ridgway, Biofouling potentials of microporous polysulfone membranes containing a sulfonated polyether-ethersulfone/polyethersulfone block copolymer: correlation of membrane surface properties with bacterial attachment, J. Membr. Sci. 157 (1999) 117-138.

[37] A. Heydorn, A.T. Nielsen, M. Hentzer, C. Sternberg, M. Givskov, B.K. Ersbøll, S. Molin, Quantification of biofilm structures by the novel computer program COMSTAT, Microbiology 146 (2000) 2395-2407.

[38] J.Y. Kim, H.K. Lee, S.C. Kim, Surface structure and phase separation mechanism of polysulfone membranes by atomic force microscopy, J. Membr. Sci. 163 (1999) 159-166.

[39] E. Ferjani, M. Mejdoub, M.S. Roudesli, M.M. Chehimi, D. Picard, M. Delamar, XPS characterization of poly(methylhydrosiloxane)-modified cellulose diacetate membranes, J. Membr. Sci. 165 (2000) 125-133.

[40] H.-L. Stoodley, P. Stoodley, Developmental regulation of microbial biofilms, Curr. Opin. Biotech. 13 (2002) 228-233.
[41] H.F. Ridgway, A. Kelly, C. Justice, B.H. Olson, Microbial fouling of reverseosmosis membranes used in advanced wastewater treatment technology: chemical, bacteriological, and ultrastructural analyses, Appl. Environ. Microbiol. 45 (1983) 1066-1084.

[42] S. Lee, M. Elimelech, Relating organic fouling of reverse osmosis membranes to intermolecular adhesion forces, Environ. Sci. Technol. 40 (2006) 980-987.

[43] D. Norberg, H. Seungkwan, T. James, Z. Yu, Surface characterization and performance evaluation of commercial fouling resistant low-pressure RO membranes, Desalination 202 (2007) 45-52.

[44] J. Martinez, D.C. Smith, G.F. Steward, F. Azam, Variability in ectohydrolytic enzyme activities of pelagic marine bacteria and its significance for substrate processing in the sea, Aquat. Microb. Ecol. 10 (1996) 223-230.

[45] H.P. Grossart, T. Kiørboe, K. Tang, H. Ploug, Bacterial colonization of particles: growth and interactions, Appl. Environ. Microbiol. 69 (2003) 3500-3509.

[46] Z. Lewandowski, H. Beyenal, Biofilm monitoring: a perfect solution in search of a problem, Water Sci. Technol. 47 (2003) 9-18.

[47] R. Long, F. Azam, Antagonistic interactions among marine pelagic bacteria, Appl. Environ. Microbiol. 67 (2001) 4975-4983.

[48] D. Jermann, W. Pronk, M. Boller, Mutual influences between natural organic matter and inorganic particles and their combined effect on ultrafiltration membrane fouling, Environ. Sci. Technol. 42 (2008) 9129-9136.

[49] C. Jarusutthirak, G. Amy, J.-Ph. Croue, Fouling characteristics of wastewater effluent organic matter (EfOM) isolates on NF and UF membranes, Desalination 145 (2002) 247-255.

[50] H. Beyenal, A. Tanyolac, Z. Lewandowski, Measurement of local effective diffusivity in heterogeneous biofilms, Water Sci. Technol. 38 (1998) 171-178.

[51] M. Hirose, H. Ito, S. Masatoshi, K. Tanaka, Highly permeable composite reverse osmosis membrane, method of producing the same, and method of using the same, US Patent 5,614,099 (1997).

[52] B. Jin, B.M. Wilén, P. Lant, Impacts of morphological, physical and chemical properties of activated flocs on dewaterbility of activated sludge, Chem. Eng. J. 98 (2004) 115-126.

[53] B.M. Wilén, B. Jin, P. Lant, The influence of key chemical constituents in activated sludge on surface and flocculating properties, Water Res. 37 (2003) 2127-2139.

[54] N. Park, B. Kwon, I.S. Kim, J. Cho, Biofouling potential of various NF membranes with respect to bacteria and their soluble microbial products (SMP): characterizations, flux decline, and transport parameters, J. Membr. Sci. 258 (2005) 43-54.

[55] M.M.T. Khan, L. Ista, A.J. Schuler, The effect of different functional surfaces to enhance $N$. europaea adsorption and biofilm formation to degrade ammonia, in: International Water Association (IWA) Biofilm Conference in UC, Davis, September 2009.

[56] Q. Li, M. Elimelech, Organic fouling and chemical cleaning of nanofiltration membranes: measurements and mechanisms, Environ. Sci. Technol. 38 (2004) 4683-4693.

[57] S. Lee, M. Elimelech, Salt cleaning of organic-fouled reverse osmosis membranes, Water Res. 41 (2007) 1134-1142.

[58] B. Kwon, S. Lee, J. Cho, H. Ahn, D. Lee, H.S. Shin, Biodegradability, DBP formation, and membrane fouling potential of natural organic matter: characterization and controllability, Environ. Sci. Technol. 39 (2005) 732-739.

[59] S.D. Arthur, Structure-property relationship in a thin film composite reverse osmosis membrane, J. Membr. Sci. 46 (1989) 243-260.

[60] Y. Zhou, S. Yu, M. Liu, C. Gao, Preparation and characterization of polyamideurethane thin-film composite membranes, Desalination 180 (2005) 189-196.

[61] M.J. Ariza, J. Benavente, E. Rodriguez-Castellon, L. Palacio, Effect of hydration of polyamide membranes on the surface electrokinetic parameters: surface characterization by X-ray photoelectronic spectroscopy and atomic force microscopy, J. Colloid Interface Sci. 247 (2002) 149-158.

[62] K. Riedl, B. Girard, R.W. Lencki, Influence of membrane structure on fouling layer morphology during apple juice clarification, J. Membr. Sci. 139 (1998) 155-166. 